\title{
Design Social: Oficina de Vassouras e pessoas com síndrome de Down
}

Social Design: Brooms workshop and people with Down Syndrome

SILVA, Geislayne Mendonça; Designer; Universidade Federal do Amazonas

geislayne94@gmail.com

SILVA, Jean Machado Maciel da; MSc; Universidade Federal do Amazonas

jeansilva@ufam.edu.br

\begin{abstract}
Resumo
A APAE-Manaus deu início a suas atividades no dia 04 de maio de 1973. Nessa associação, os alunos com síndrome de Down participam de Oficina de Vassouras onde os mesmos são levados ao desenvolvimento cognitivo por meio de atividades laborais. No entanto, foram identificados alguns problemas no ambiente de trabalho como erro quanto à postura, disposição dos itens e falta de ferramenta adequada para realização das atividades. Portanto o objetivo do trabalho foi criar ferramentas e organizar o ambiente proporcionando conforto e segurança para a realização de tarefas que estimulem a prática de atividades laborais, uma vez que o objetivo da própria associação é oferecer a prática de exercícios através da Oficina de Vassouraria sem a intenção de produzir e vender, porém, por meio dessa atividade estimular o desenvolvimento físico e intelectual dos alunos portadores da síndrome de Down.
\end{abstract}

Palavras Chave: Inclusão Social; APAE-Manaus; Design de Produto.

\begin{abstract}
APAE-Manaus started its activities on May 4, 1973. In this association, students with Down syndrome participate in a Brooms Workshop where they are led to cognitive development through work activities. However, some problems in the work environment were identified as error regarding posture, arrangement of items and lack of adequate tool to carry out the activities. Therefore, the objective of the work was to create tools and organize the environment, providing comfort and safety to perform tasks that stimulate the practice of work activities, since the purpose of the association itself is to offer the practice of exercises through the Brooms Workshop without the intention to produce and sell, but through this activity stimulate the physical and intellectual development of students with Down syndrome.
\end{abstract}

Keywords: Social Inclusion; APAE-Manaus; Product Design. 


\section{Introdução}

A exclusão social trata-se de um problema evidente na sociedade, sendo esta segregação de indivíduos causada pelos mais diversos motivos como condição financeira ou necessidades especiais. Constata-se que pessoas portadoras de Síndrome de Down também são excluídas socialmente, sendo que a síndrome em si não é uma doença, mas uma ocorrência genética. A forma como a criança é recebida pela família e, a partir de então, cuidada pela mesma poderá afetar de forma significativa o desenvolvimento intelectual da criança. A superproteção também é um agravante para o comprometimento do seu desenvolvimento social e intelectual. Acarretando prejuízos quanto ao convívio social e profissional na fase jovem e adulta e quanto a relações interpessoais e dificuldades concernentes a hierarquia de empresas ou estabelecimentos. A preparação da equipe de trabalho que irá receber a pessoa com síndrome de Down é importante.

Há atividades que requerem um pouco mais de atenção quando executadas por pessoas que possuem deficiência intelectual e múltipla (isso inclui portadores de síndrome de down). Quanto a deficiência intelectual, Sousa et al. (2008, p. 06) afirma que:

\footnotetext{
Uma das áreas mais extensivamente estudadas no âmbito da deficiência intelectual tem sido a do desenvolvimento e funcionamento cognitivos. na verdade, as principais manifestações desta deficiência situam-se na menor eficiência em situações de aprendizagem, de aquisição de aptidões e de resolução de problemas. Dois modelos teóricos opostos têm caracterizado a deficiência intelectual como um simples atraso no desenvolvimento (modelo desenvolvimentista), ou como a expressão de défices qualitativos específicos (modelo deficitário ou da diferença).
}

Brasil (1994, p.15) apud Silva (2011, p. 02) define que a deficiência múltipla é a associação, no mesmo indivíduo de duas ou mais deficiências primárias (mental/visual/auditivo-física), com comprometimentos que acarretam atrasos no desenvolvimento global e na capacidade adaptativa. Em visita realizada a APAE-Manaus pode-se observar as diferentes limitações que cada um dos envolvidos com a oficina de vassoura apresentava, uns tinham sua capacidade cognitiva mais desenvolvida e conseguiam realizar atividades mais complexas, diferente de outros. $O$ ato de unir o cabo da vassoura ao cepo (peça de madeira onde os tufos de nylon são fixados) por meio de pregos era uma das atividades que exigiam mais de uns e menos de outros. O problema pôde ser identificado na execução das atividades. O modo como o aluno se posicionava para pintar o cabo era prejudicial para sua saúde física, o que podia levá-lo a desenvolver complicações como lesões na coluna vertebral. Conforme lida (2005) o fator mais importante no dimensionamento do espaço de trabalho é a postura assumida. Existem três posturas básicas para o corpo: deitada, sentada e de pé. No caso em questão, a postura era a de pé. Constatou-se, também, a dificuldade enfrentada para a realização das aparas necessárias ao alinhamento das bruxinhas presas ao cepo, essa atividade estava sendo realizada com o auxílio de uma tesoura comum que não é a ferramenta ideal, pois é destinada a realização de corte em materiais como tecido e papel dificultando assim a execução da mesma por parte dos alunos. A organização do layout do ambiente (área em que são realizadas as atividades) e as ferramentas fornecidas as quais não apresentam boas condições por conta da falta de manutenção, proporcionam dificuldades aos alunos na realização das tarefas.

Em Manaus (e em outras localidades do Brasil) as pessoas portadoras da síndrome de Down podem ter acesso a APAE (Associação de Pais e Amigos dos Excepcionais) onde, por meio de 
atividades e programas, a mesma busca potencializar as chances de desenvolvimento de crianças, jovens e adultos com deficiência intelectual e múltipla visando fazer com que essas pessoas sejam plenas em suas realizações pessoais, independentes e auto realizadas. Capazes de ingressarem no mercado de trabalho ou em outra área da sociedade, e neste ambiente desenvolverem as atividades que Ihes forem apresentadas e resolver situações que Ihes forem impostas. Uma das atividades que a APAE-Manaus oferece é a oficina de vassouras onde os alunos com síndrome de Down são submetidos a prática de exercícios laborais no intuito de que haja desenvolvimento cognitivo dos mesmos. A síndrome de Down, conforme Bissoto (2005, p. 02), se caracteriza, em sua etiologia, por ser uma alteração na divisão cromossômica usual, resultando na triplicação - ao invés da duplicação - do material genético referente ao cromossomo 21 . Saad $(2003$, p. 01) afirma que:

\begin{abstract}
Constata-se ultimamente, cada vez mais, o desempenho relevante de pessoas com síndrome de Down que tiveram oportunidade de desenvolver suas potencialidades, nas mais diversas áreas do conhecimento. Algumas afirmações de estudiosos ligados à área da deficiência mental enfatizam que as pesquisas existentes, referentes à síndrome de Down, são ainda insuficientes para esclarecer e guiar atitudes educacionais para o desenvolvimento das pessoas que a apresentam.
\end{abstract}

Diante de tal afirmação pode-se entender que há a necessidade de que as pessoas portadoras da síndrome sejam orientadas ao desempenho de suas potencialidades de forma que as mesmas possam ingressar o mercado de trabalho uma vez preparadas para tal. Gomes-Machado (2009, p. 02) afirma que:

De acordo com a Organização Mundial da Saúde, o emprego protegido ainda constitui a principal forma de ocupação para jovens e adultos com DI (66\%). Já as situações de inclusão profissional nas quais os empregados com DI compartilham o mesmo local de trabalho com outros funcionários, dentro das empresas, têm índice bem menor (44\%). Do mesmo modo, aponta-se correlação entre elevada renda do país e maior número de programas de inclusão profissional para pessoas com DI (WHO, 2007, p. 47).

O desenvolvimento cognitivo do portador de Síndrome de Down se mostra usualmente marcado por concepções tradicionalmente estabelecidas e sedimentadas, que acabam por assumir o caráter de inquestionáveis, balizando as perspectivas e práticas adotadas nos procedimentos de reabilitação e na educação familiar e escolar (BISSOTO, 2005). Simonetti (2012) afirma que:

\footnotetext{
Cognição refere-se a um conjunto de habilidades cerebrais/mentais necessárias para a obtenção de conhecimento sobre o mundo. Tais habilidades envolvem pensamento, raciocínio, abstração, linguagem, memória, atenção, criatividade, capacidade de resolução de problemas, entre outras funções." O conceito de cognição, portanto, nos remete aos processos cognitivos que são desenvolvidos desde a mais tenra infância até os findos anos do envelhecimento. Importante notar que o desenvolvimento está diretamente relacionado à aprendizagem, ou seja, um não ocorre sem o outro.
}

A temática da pesquisa está inserida em duas importantes áreas do design que é o Design de produto e o Design social. Sendo a mesma motivada pela busca de criar meios e ações que combatam a exclusão social, por meio do Design de Produto e Design Social. Não sendo uma ação que transformou de forma radical a condição das pessoas com síndrome de Down alunas da APAEManaus, mas foi uma ação que objetivou iniciar este processo, possibilitando a inclusão destas pessoas no mercado de trabalho por meio da preparação das mesmas através de atividades laborais 
utilizando ferramentas que facilitem a prática das mesmas sem descaracterizar a intenção dos exercícios, que visa estimular o desenvolvimento intelectual e motor destas pessoas. Cujo objetivo geral foi criar ferramentas que auxiliem as pessoas com Síndrome de Down e organizar o ambiente proporcionando conforto e segurança para a realização de tarefas que estimulem a prática de atividades laborais. O presente artigo contempla diferenças projetuais entre trabalhadores regulares e associados a terapias de desenvolvimento no que tange concepção de produtos, uma vez que é baseado em dados antropométricos com percentis 5 para homens e mulheres. Desta forma, é totalmente voltado para desenvolvimento de soluções projetuais apenas para a comunidade de pessoas portadoras de síndrome de Down vinculadas a APAE-Manaus.

\section{Metodologia}

Foi realizado um levantamento bibliográfico onde a pesquisa se propôs a investigar os aspectos funcionais que envolvem a confecção de vassouras e a prática de atividades laborais por pessoas portadoras da síndrome de Down. Para tanto, foram trabalhados os seguintes conceitos objetivando executar o projeto:

a) Espaço de trabalho - direcionado para a investigação e definição dos elementos constituintes do espaço de trabalho além do arranjo organizacional. Objetivou fazer estudos quanto ao layout e a forma final de cada produto a ser gerado levando em consideração as especificidades do público-alvo ao qual foi destinado o trabalho.

b) Pintura de cabo de vassoura - voltado para o estudo de materiais e formas de configuração espacial, de postura, tipos de atividades manuais e pediosas, manejo fino e grosseiro.

c) Guilhotina para cerdas de vassouras - centrado em critérios específicos voltados para o ato de guilhotinar, identificando tipos de lâminas de corte, sistemas de segurança, melhor posicionamento para realização desta atividade.

d) APAE-Manaus - buscando expor a origem e as atividades realizadas pela associação em busca de inclusão social por meio de ações sem fins lucrativos além de abordar o conceito básico de síndrome de Down e de desenvolvimento cognitivo.

Foram adotados, para o desenvolvimento do trabalho, procedimentos como pesquisa bibliográfica, considerando apenas os aspectos centrados no design de produto, voltado para a concepção de novos produtos, informações acerca de soluções similares existentes no mercado, e, por último, aplicação de conceitos ergonômicos durante a idealização das alternativas. Houve consulta de mercado, observando os similares existentes e o posicionamento do público alvo (pessoas com síndrome de Down e deficiência intelectual e múltipla) além de pessoas que trabalham com a implementação de oficinas de vassouras. Os dados foram analisados, verificando os prós e os contras das informações coletadas para a geração de proposta compatível ao objetivo geral da pesquisa. Os protótipos virtuais das alternativas foram gerados a partir dos softwares Solid Edge e CorelDRAW.

A metodologia utilizada para o desenvolvimento da pesquisa foi a mescla de metodologias apresentadas por Barbosa Filho (2009) e Gui Bonsiepe. Sendo as diretrizes propostas por Barbosa 
Filho (2009) mais voltadas para o desenvolvimento do produto em si consistindo em: Levantamento da demanda; Construção do Conceito; Definição funcional; Geração de alternativas; Materialização de alternativas; Realização de testes e Apresentação da solução final. A metodologia proposta por Bonsiepe foi utilizada para o desenvolvimento de toda a pesquisa onde inicia-se a partir da formulação do problema e conclui-se com a prova de protótipos. Os requisitos e parâmetros projetuais foram definidos a partir de conceitos de design universal e ergonomia propostos por lida (2005) e de diretrizes propostas por Pazmino (2007, p. 04).

\begin{tabular}{|c|c|}
\hline REQUISITOS & PARÂMETROS \\
\hline \multicolumn{2}{|c|}{ ESPAÇO DE TRABALHO } \\
\hline $\begin{array}{l}\text { Deve possibilitar um melhor aproveitamento } \\
\text { do ambiente tanto para que as atividades laborais } \\
\text { como para que as vassouras sejam confeccionadas } \\
\text { com mais facilidade. }\end{array}$ & $\begin{array}{l}\text { Aplicar estudos de arranjo organizacional ou } \\
\text { layout de produção. }\end{array}$ \\
\hline \multicolumn{2}{|c|}{ DISPOSITIVO PARA PINTAR CABO DE VASSOURA } \\
\hline Deve ser de uso simples e intuitivo & Aplicar princípios de ergonomia. \\
\hline Ótima adequação entre produto e usuário & $\begin{array}{l}\text { Conceitos ergonômicos que consideram as } \\
\text { limitações do usuário. }\end{array}$ \\
\hline $\begin{array}{l}\text { Facilidade quanto a troca de peças, transporte, } \\
\text { desmontagem e fixação. }\end{array}$ & $\begin{array}{l}\text { Fazer uso de formas mais geométricas e } \\
\text { simples para a idealização deste produto. }\end{array}$ \\
\hline \multicolumn{2}{|c|}{ EQUIPAMENTO PARA GUILHOTINAR CERDAS } \\
\hline Lâmina de corte não aparente & $\begin{array}{l}\text { Anteparo que impossibilite a visualização da } \\
\text { lâmina. }\end{array}$ \\
\hline $\begin{array}{l}\text { Acionamento de alavanca após identificação de } \\
\text { cepo no espaço para corte }\end{array}$ & $\begin{array}{l}\text { Subsistemas que possibilitem a identificação } \\
\text { do cepo e que destravem a alavanca para uso da } \\
\text { guilhotina. }\end{array}$ \\
\hline $\begin{array}{l}\text { Facilidade quanto ao transporte em meio ao } \\
\text { espaço de trabalho }\end{array}$ & Fazer uso de sistemas de rodízios embutidos. \\
\hline $\begin{array}{l}\text { Posicionamento para guilhotinar que beneficie } \\
\text { os usuários e que não exija muita força física, mas } \\
\text { que estimule o desenvolvimento cognitivo }\end{array}$ & $\begin{array}{l}\text { Aplicar estudos de posicionamento em } \\
\text { ambientes de trabalho. }\end{array}$ \\
\hline
\end{tabular}

Fonte: elaborado pelo autor (2017). 


\subsection{Geração de alternativas}

Visando atender o objetivo geral da pesquisa foram desenvolvidos três produtos distintos entre si que atuam em um mesmo ambiente com o intuito de proporcionar melhores condições para a realização das atividades propostas na oficina de vassouras.

\subsubsection{Espaço de Trabalho}

Foi gerada uma única alternativa de layout para a sala da oficina de vassouras da APAEManaus. A mesma teve como finalidade criar nexo entre as bancadas, mesas e ferramentas para um melhor desempenho das atividades desenvolvidas pelos alunos. Obedecendo ao arranjo celular de layout onde as atividades são feitas por partes e não como em uma linha de produção, visto que o objetivo é realizar atividades voltadas para exercícios laborais dos alunos envolvidos.

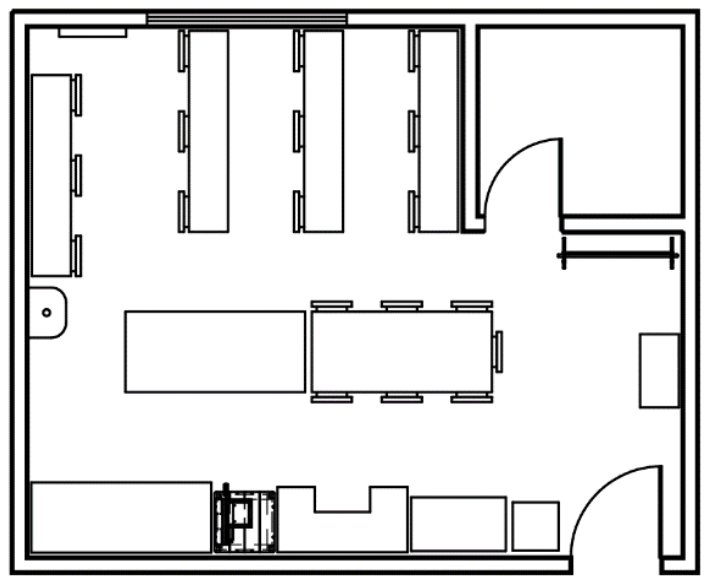

Figura - 01 Alternativa proposta de layout.

\subsubsection{Dispositivo para pintar cabo de vassoura}

Levando em consideração as diretrizes e requisitos e parâmetros estabelecidos, buscou-se gerar apenas uma alternativa de fácil manipulação. Para isso foram esboçadas ideias e realizadas comparações antropométricas para que a mesma fosse simples e eficaz. Assim, um aramado de perfil metálico com pontos de solda veio a ser a alternativa proposta.

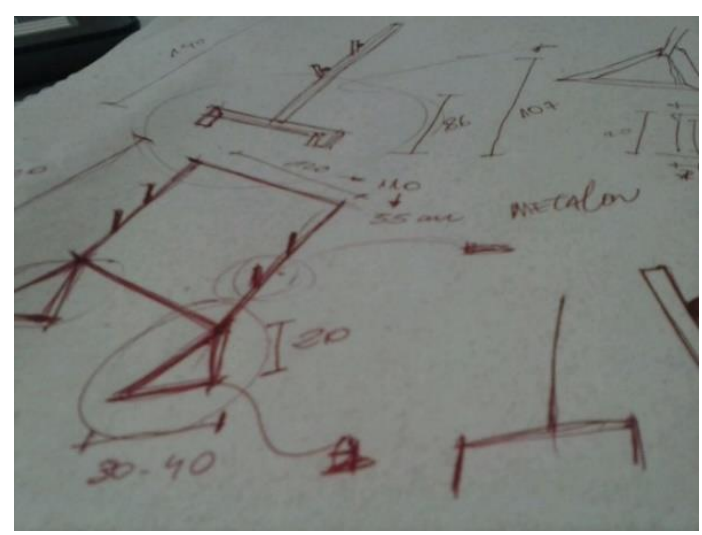

Figura 02 - Desenvolvimento da alternativa de dispositivo para pintura. 


\subsubsection{Equipamento para guilhotinar cerdas}

Em um primeiro momento pensou-se no conjunto como um todo: bancada e guilhotina. $\mathrm{Na}$ FIGURA 03 temos: a entrada do material a ser processado (1), o processo (2) e a saída (3); onde em (1) o cepo com as cerdas ainda não processadas são acomodadas, em (2) ocorre o processamento e em (3) temos o material processado e finalizado quanto a essa etapa.

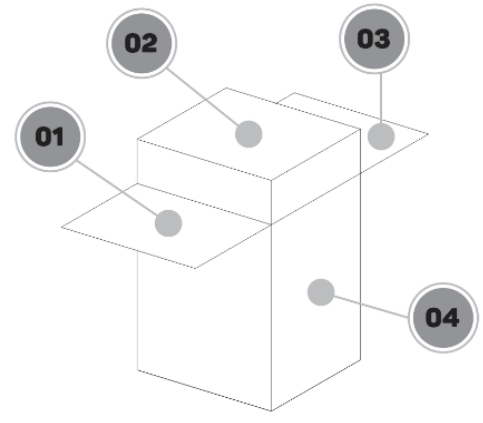

Figura 03 - Esquema inicial de bancada e guilhotina.

\subsubsection{Bancada - Alternativa Proposta}

A alternativa a princípio contava com duas abas laterais para acomodação dos cepos com as cerdas processadas e não processadas, área de trabalho para corte com espaço para descarte de resíduos e área para coleta de resíduos.

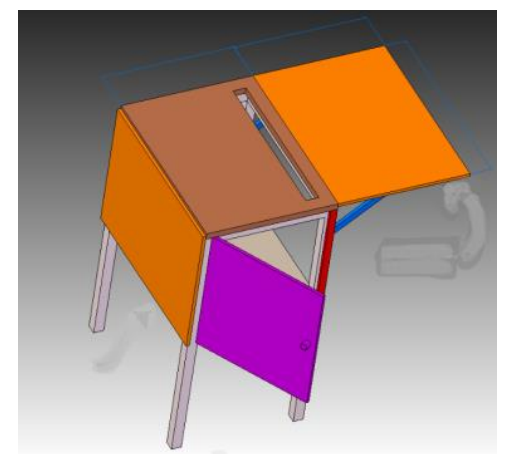

Figura 04 - Alternativa inicial de bancada. Modelagem 3D.

Quanto a área de trabalho da bancada, conforme as medidas de áreas de alcance máximo e ótimo dos braços (IIDA, 2005), foi definida área menor (A) e a área máxima (C), medindo respectivamente $30 \mathrm{~cm}$ e $160 \mathrm{~cm}$, onde 1 e 3 são as denominadas abas laterais e 2 é a área em que ocorre a ação de corte das cerdas como ilustra a FIGURA 05.

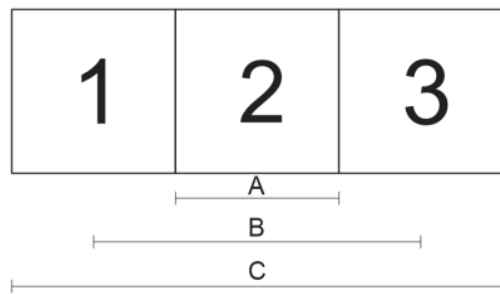

$A=30 \mathrm{~cm}$

$\mathrm{B}=100 \mathrm{~cm}$

C $=160 \mathrm{~cm}$

Figura 05 - Relações espaciais de área ótima para trabalho. 
A altura da bancada também foi definida a partir das alturas relacionadas para cada tipo de trabalho (IIDA, 2005) e da média entre as alturas máxima e mínima, tendo em vista a realização de trabalhos pesados que exigem aplicação maior de força visto que os alunos da APAE com síndrome de Down dispõem de uma estatura mais baixa que o padrão para homens e mulheres. Questionamentos quanto a utilização do espaço e manipulação por parte dos alunos foram levantados e a alternativa sofreu algumas alterações. As abas laterais foram retiradas e junto ao espaço para descarte de resíduos foi adicionada uma peça para impedir que os resíduos fossem espalhados (FIGURA 06). A amarração das pernas da bancada foi propositalmente colocada de forma a servir de suporte para descanso dos pés com altura de $20 \mathrm{~cm}$. A área de coleta dos resíduos também foi retirada.

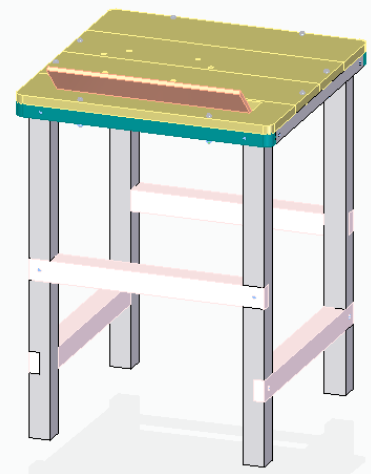

Figura 06 - Alternativa de bancada finalizada em modelagem 3D.

\subsubsection{Guilhotina}

Foram geradas duas alternativas de guilhotina e feita a seleção conforme diretrizes e requisitos e parâmetros propostos.

\section{Alternativa 01}

$\mathrm{O}$ ato de cortar algo pode se transformar em um grave acidente e resultar em mutilação de membros do corpo. Levando em consideração a afirmação anterior, a alternativa desenvolvida dispõe de um sistema diferente do padrão e conta com um sistema que impede a visualização parcial da lâmina e restringe o contato direto com o usuário. Para confecção de todo o sistema seriam necessários aços especiais e usinagem com ferramentas apropriadas para aços mais duros. Na FIGURAS 07 têm-se a peça identificada na cor preta cuja função é impedir a visualização parcial da lâmina e o contato direto por parte do utilizador.

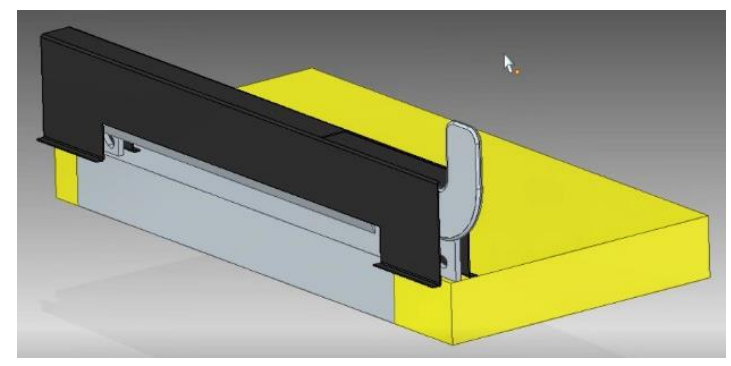

Figura 07 - Guilhotina com chapa para proteção. 


\section{Alternativa 02}

Para a geração da segunda alternativa foi feito um estudo para definir o posicionamento do ponto fixo para movimentação da lâmina, ângulo de abertura da mesma e seu posicionamento em relação aos demais itens do sistema de corte. Ao todo foram feitas onze análises e a última foi escolhida para desenvolvimento da alternativa pelos seguintes motivos: em relação a primeira análise a última apresentou o menor ângulo de abertura entre a aresta da faca e a da contra faca, o ponto fixo está posicionado na peça de cantoneira laminada e a faca não ultrapassa a peça de madeira (FIGURA 08). Para melhor entendimento, temos a FIGURA 09 onde 01 e 02 são peças de madeira onde o cepo com as cerdas a serem alinhadas serão colocados, 03 é a contra faca confeccionada a partir de cantoneira laminada, 04 é a peça de cantoneira laminada para o ponto fixo. As peças caracterizadas pela cor rosa (01) na FIGURA 09 compreendem a área de corte do sistema.
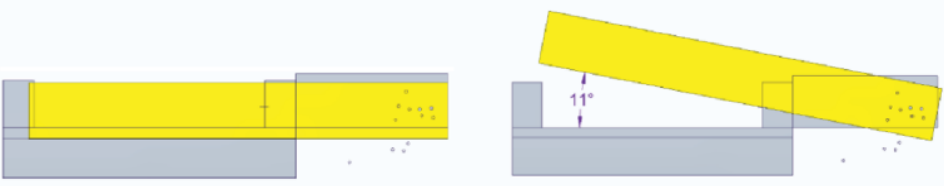

Figura 08 - Última análise realizada.

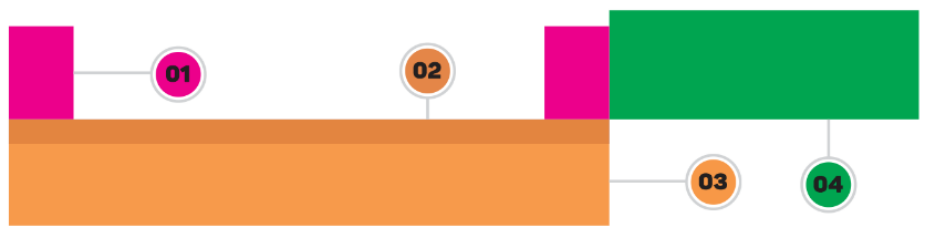

Figura 09 - Esquema para identificação através da cor.

O ângulo de $11^{\circ}$ compreende a altura necessária para a acomodação das cerdas de no mínimo $20 \mathrm{~mm}$ e no máximo $25 \mathrm{~mm}$, visto que quanto maior a altura maior o índice de periculosidade para os usuários. O software Solid Edge foi utilizado para a modelagem 3D buscando melhor visualização da configuração da alternativa. Esta última alternativa de guilhotina foi selecionada e seu protótipo foi confeccionado (FIGURA 10). No protótipo físico foram percebidos impasses não visualizados no protótipo digital como: dificuldade para realização do corte por conta do aço escolhido para confecção da faca e contra faca (cantoneiras laminadas de "aço doce"). As modificações foram realizadas e a contra faca passou a ser uma lâmina de desengrossadeira de aço carbono e a faca passou a ser de barra chata de aço VC K100. O protótipo físico da bancada também foi confeccionado (FIGURA 10).

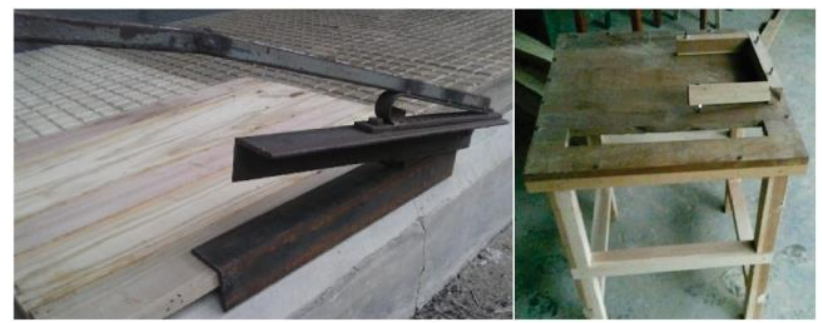

Figura 10 - Protótipo físico de guilhotina e protótipo físico de bancada. 


\subsection{Detalhamento técnico}

\subsubsection{Espaço de trabalho}

A segmentação por cor na FIGURA 11 representa a disposição das ferramentas, mesas e bancadas a serem utilizadas na realização das atividades. Em vermelho temos a área das bancadas onde atividades como contagem de cerdas para montagem das bruxinhas, corte de arames e detalhes podem ser executados. Em verde temos as mesas que podem ser usadas externamente a sala para atividades como pintura de cepos, além de servir como suporte para as vassouras prontas. Em azul temos as ferramentas para desfiação de pet, corte para alinhamento de cerdas (guilhotina e bancada) e prensagem das bruxinhas, mesa auxiliar e armário, na parte amarela temos o dispositivo para pintura de cabos.
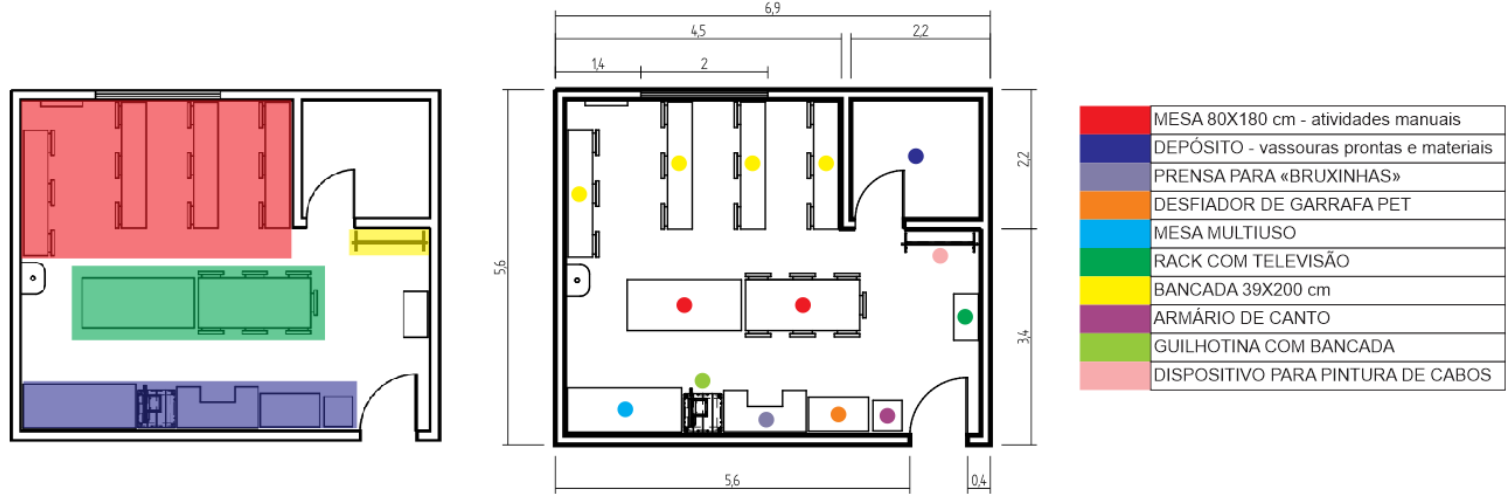

Figura 11 - Segmentação de atividades por cor e detalhamento da alternativa proposta de layout.

\subsubsection{Dispositivo para pintar cabo de vassoura}

A altura estabelecida tanto para a posição em pé quanto sentado partiram de tabela de dimensões corporais/1985 de percentis 5 para homens e mulheres (PANERO e ZELNIK 2013). Onde a altura estabelecida para a posição em pé foi de $168,2 \mathrm{~cm}$ e para a posição sentado foi de $86 \mathrm{~cm}$ (FIGURA 12). O material proposto para confeç̧ão do dispositivo foi perfil quadrado de $20 \times 20 \mathrm{~mm}$ com espessura de parede $1,5 \mathrm{~mm}$. A junção das peças de perfil posteriormente cortado é realizada através da solda por eletrodo revestido. Para acabamento, o dispositivo pode ser pintado e adicionado alguns protetores em suas extremidades.
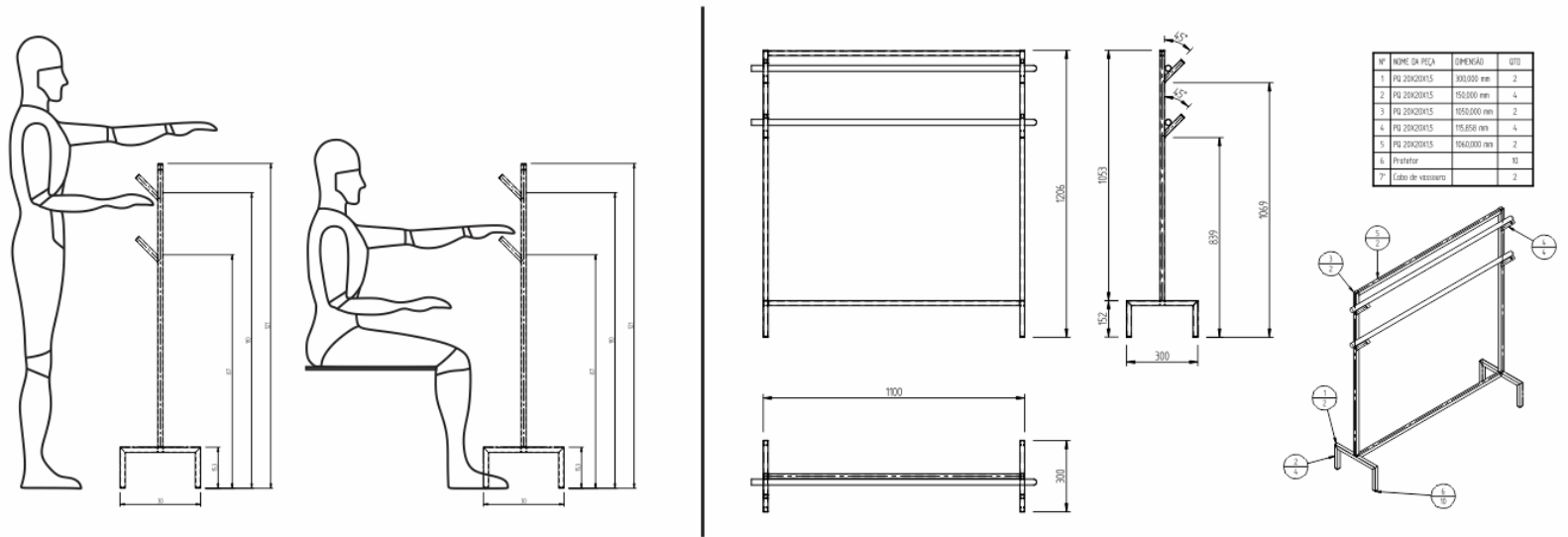

Figura 12 - Relação homem-ferramenta posição em pé e posição sentado e medidas gerais. 


\subsubsection{Equipamento para guilhotinar cerdas}

A altura de usuário utilizada foi de $168,2 \mathrm{~cm}$. Onde, em repouso, a área de contato da alavanca da guilhotina encontra-se a uma altura de $102 \mathrm{~cm}$. Para confeç̧ão da bancada foram necessárias peças de madeira como tábuas e pernas mancas, parafusos, porcas e arruelas, ferramentas básicas de marcenaria e poucas operações. O material da contra faca é aço carbono, a lâmina usada como contra faca foi proveniente de desengrossadeira. A barra chata utilizada como lâmina tem como material o aço VC $131 \mathrm{~K} 100$ 6×50×400 mm, utilizado para confecção principalmente de lâminas de corte e trabalhos a frio como estampagem. A alavanca foi confeccionada a partir de metalon perfil

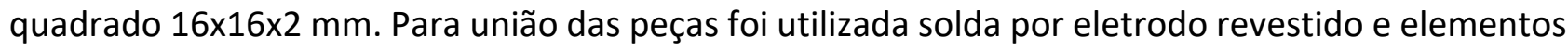
de ligação como parafuso Allen sextavado interno.

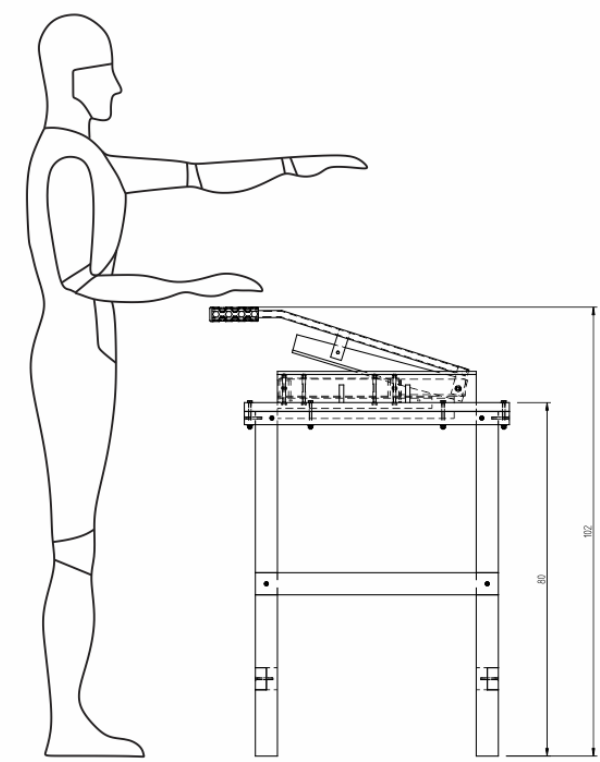

Figura 13 - Relações de altura entre usuário e ferramenta.
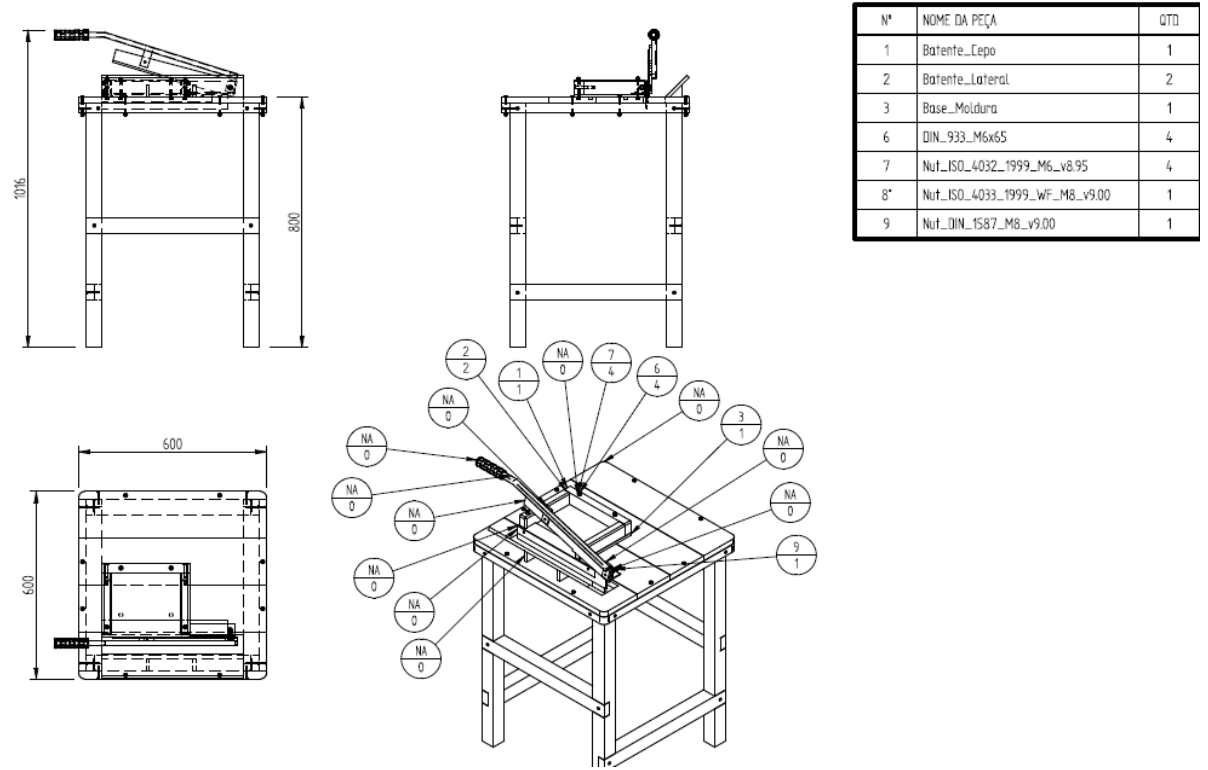

Figura 14 - Vistas gerais guilhotina e bancada 


\section{Resultados}

Quanto ao espaço de trabalho, os únicos itens adicionados ao layout original da oficina foi o Dispositivo para pintura de cabos de vassouras, Guilhotina e bancada e um total de sete (07) cadeiras. Os demais itens no layout já existiam no local. As medidas foram coletadas para que a planta baixa do local fosse gerada e pudessem ser realizadas as análises quanto ao melhor aproveitamento do espaço e disposição dos elementos. O protótipo físico do Dispositivo para pintura não foi produzido, mas em compensação foi modelado no software Solid Edge. As relações de altura entre o usuário e o protótipo foram feitas graficamente no software CorelDRAW. A estrutura proposta é simples e não requer muitos materiais, apenas metalon (perfil metálico quadrado $20 \times 20 \times 1,5 \mathrm{~mm}$ ) e solda por eletrodo revestido para unir as partes. $O$ dispositivo pode ser pintado e para acabamento das extremidades têm-se protetores de plástico.
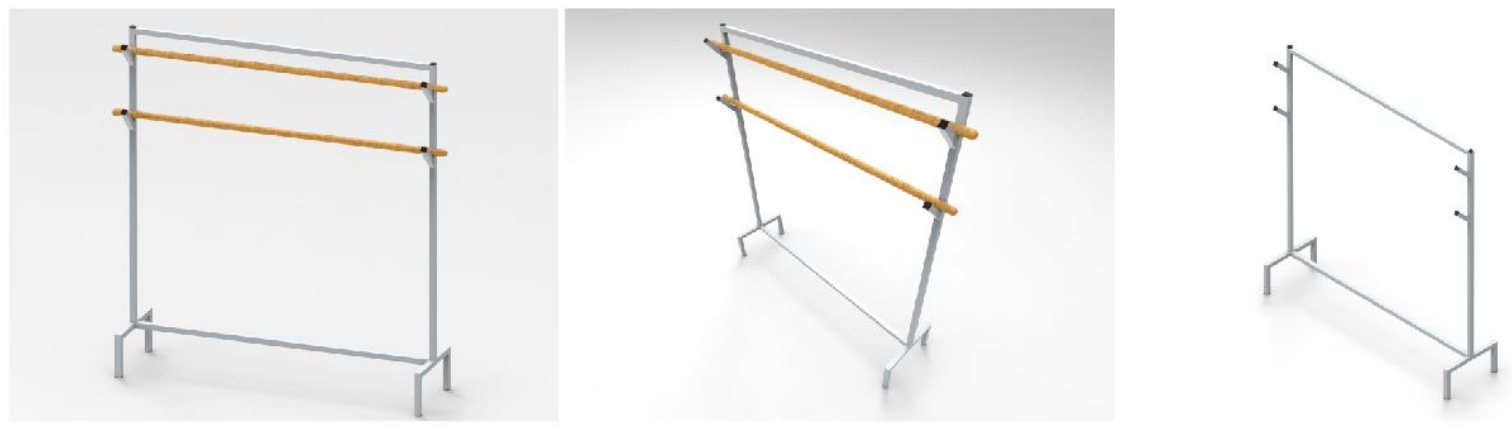

Figura 15 - Dispositivo para pintura de cabos de vassoura com simulação de dispositivo e cabos de vassouras nas duas alturas. Fonte própria, 2017.

O protótipo físico da bancada foi concluído, mas para melhor exibição dos resultados utilizou-se o protótipo virtual, uma vez que a alteração feita na guilhotina quanto a substituição da faca, que antes era uma peça de cantoneira laminada de "aço doce" e foi substituída por barra chata de aço VC $131 \mathrm{~K} 100$, até o fechamento do trabalho ainda não tinha sido concluído seu processo de usinagem. Então, para demonstração de resultados, os protótipos aqui mostrados são virtuais modelados no software Solid Edge.

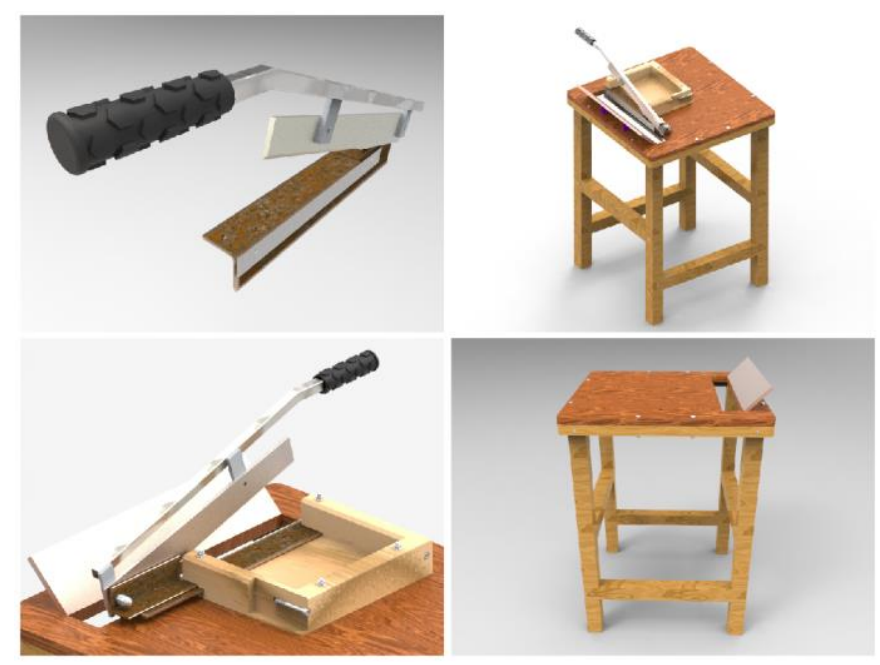

Figura 16 - Protótipo virtual de Bancada e guilhotina. Fonte própria, 2017. 


\section{Conclusão}

A proposta de seguir a linha de Design Social implica em várias questões inclusive conceitos pessoais acerca do que vem a ser Design de fato. A busca por soluções inovadoras envolvendo desafios durante o processo de fabricação e novos materiais não veio a ser o foco do trabalho, uma vez que a inovação não está atrelada apenas a itens de alto valor agregado e processos complexos. O maior desafio foi estabelecer que soluções aparentemente simplórias também são soluções de Design cujo objetivo é atender as necessidades reais dos usuários, ainda mais se tratando de inclusão social onde o menos é mais se bem aplicado. Quanto aos resultados alcançados pode-se destacar que não houve muita dificuldade para chegar a solução final tanto para o layout proposto quanto para o dispositivo para pintura dos cabos de vassouras. As soluções propõem fácil execução e manipulação por parte dos usuários. A alternativa final da guilhotina e bancada tomou mais tempo desse trabalho, uma vez que exige maior atenção quanto a escolha do material, processo de fabricação, interação homem e ferramenta, relações antropométricas e de espaço. A produção do protótipo físico da guilhotina e bancada foi essencial para encontrar impasses não percebidos na modelagem 3D, podem ser citados impasses como não realização do corte das cerdas de nylon por conta do aço escolhido para confeç̧ão da lâmina, aresta não cortante da contra faca também por conta do material escolhido. 


\section{Referências}

BARBOSA FILHO, A.N. 2009. Projeto e desenvolvimento de produtos. Atlas, São Paulo, 182p.

BISSOTO, M. L. Desenvolvimento cognitivo e o processo de aprendizagem do portador de síndrome de down: revendo concepções e perspectivas educacionais. 2005. Centro Universitário de Araras Dr. Edmundo Ulson, SP, Brasil.

GOMES-MACHADO, M. L; CHIARI, B. M. Estudo das Habilidades Adaptativas Desenvolvidas por Jovens com Síndrome de Down Incluídos e não Incluídos no Mercado de Trabalho. 2009. Saúde Social, São Paulo, v.18, n.4, p.652-661.

IIDA, I. 2005. Ergonomia: projeto e produção. 2da ed. Blucher, São Paulo, 614p.

PANERO, J.; ZELNIK, M. Dimensionamento humano para espaços interiores. Gustavo Gili, Barcelona, 2008, 320p.

PAZMINO, A. V. Uma reflexão sobre Design Social, Eco Design e Design Sustentável. In: I Simpósio Brasileiro de Design Sustentável. 2007, Curitiba. Anais eletrônicos.

SAAD, S. N. Preparando o caminho da inclusão: dissolvendo mitos e preconceitos em relação à pessoa com síndrome de down. Rev. Bras. Ed. Esp., Marília, Jan.-Jun. 2003, v.9, n.1, p.57-78

SILVA, Y. C. R. Deficiência múltipla: conceito e caracterização. 2011, Encontro Internacional de Produção Cientifica - VII EPCC. Disponível em: https://www.unicesumar.edu.br/epcc-2011/wpcontent/uploads/sites/86/2016/07/yara_cristina_romano_silva3.pdf

SIMONETTI, L. O que é desenvolvimento cognitivo? 2012. Disponível em: https://cienciadocerebro.wordpress.com/2012/09/05/o-que-e-desenvolvimento-cognitivo/

SOUSA, R.; BELO, C.; CARIDADE, H.; CABRAL, L. Deficiência Intelectual: Terminologia e Conceptualização. 2008. Disponível em: http://www.madeiraedu.pt/Portals/7/pdf/revista_diversidades/revistadiversidades_22.pdf\#page=4 